\title{
On construction of tax law course evaluation system
}

\author{
Jie Li \\ Wuchang University of Technology, Wuhan, 430223, China
}

Keywords: exploitation internalization; quality-based topic; semi-closure; super-value credit

\begin{abstract}
. tax law course is a course with strong theoretical property, practicalness and timeliness. Most national fiscal revenue comes from tax revenue. Tax revenue is closely related to every one in current society. To be familiar with tax law and able to complete tax handling is the essential requirements for tax accountants. But current teaching evaluation system is limited to attendance and examination paper in the end of the term. These fail to reflect cultivation of students' tax handling ability through tax law course. This paper starts from the quality and ability required by current society for a tax accountant to analyze the problems of college tax law course evaluation system and propose views the author.
\end{abstract}

\section{Quality and ability required by tax accounting post}

The knowledge learned in tax law course corresponds to tax accounting posit in actual work. The author participated in revision of nationwide accountancy classification in 2010 and surveyed quality and ability requirements for tax accountants. The survey involves 6 large enterprises, over 20 small and medium enterprises as well as 6 accounting firms. Enterprise requirements of college graduates for tax accounting include three categories: 1. professional tax knowledge; 2 . practical tax skills; 3. other comprehensive quality requirements. Seeing from enterprise recruitment, they pay more attention to professional skills of tax accountants, i.e. the ability to handle tax-related problems.

1. Quality system requirement

Enterprises' general requirements for tax accountants include the following: familiar with national financial policies, tax policies and regulations; familiar with relevant financial regulations; love the post and devote wholeheartedly to work; own good professional ethics, careful working style, strong working principles and strong working enthusiasm and sense of responsibility; handle daily official documents.

2. Ability requirement

For tax accounting post, it is necessary to grasp the latest finance and tax information and operate tax-related business of tax payers according to taxation requirements, such as buying invoice, issuing invoice, verify invoice, certificate invoice and copy tax regularly. Besides, it is required to record, calculate and summarize tax liability of tax payers and tax payment situations, prepare tax payment application forms, declare according to liability of tax payers, pay tax payable timely, timely control and inspect tax liability and tax payment situations of tax payers, and correct internal unlawful act. According to requirements of tax law, it is required to operate the accounting information system to handle tax-related business and account relevant economic business.

\section{Current situation of tax law evaluation system in universities}

The above analyzes enterprise requirements for tax accounting knowledge, ability and quality. Whether students cultivated by tax law courses can meet actual enterprise needs? Through survey of some college teachers, students and enterprises, current tax law course evaluation modes mainly include the following:

1. Traditional $30 \%+70 \%$

Traditional $30 \%+70 \%$ is widely applied in many colleges. The main implementation mode is as follows: ordinary performance $30 \%$ which is composed of attendance and assignments $+70 \%$ score of final examination which is composed of testing the memory of theoretical knowledge and tax law 
calculation. Under such mode, students only pay attention to theoretical knowledge and cannot form actual operation ability. Besides, most students make effort at the last moment in the final examination and do not master theoretical knowledge solidly.

2. Complete practice type

Such examination mode is often applied in some vocational colleges. Colleges employ tax accountants from enterprises to teach students. It takes one week or two weeks to simulate the working process of tax accounting post and complete tax declaration for various taxes or 1-2 months. Then, the grade is evaluated according to tax declaration form and working process. Such mode has great help for cultivating students' practical ability. However, flexibility in practical work decides some processes may not be handled normatively. Complete practical ability cultivation may cause that students do not know how the tax payment is completed. Thus, the theory and practice are disconnected.

\section{Combined theory and practice}

Combined theory and practice is a common evaluation mode adopted by colleges. Tax law teaching and evaluation are composed of two parts: theory and practice. The theoretical part is based on traditional $30 \%+70 \%, 40 \%+60 \%$ or $50 \%+50 \%$. For the practical part, teachers or enterprise personnel will lead student to complete tax calculation and tax declaration with financial software and score them according to performance. The final score forms in combination of the two parts. Such mode considers cultivation of theoretical knowledge and practical ability. But limited to course system setting and actual soft hardware conditions, some formalistic circumstances occur sometimes. The actual function is not exerted.

\section{New thought of constructing tax law course evaluation system}

Regardless of traditional evaluation, complete practice type or combined theory and practice, they have problems and operation difficulties. In combination of advantages of the thee modes, actual teaching situations of colleges as well as enterprise requirement for tax accountants, exploitation internalization teaching method, quality-based topic in the end of term and super-value credit can be used to perfect tax law course evaluation system.

1. Exploitation internalization teaching method

Exploitation internalization teaching mode based on the precondition of mobilizing students' autonomous learning enthusiasm aims to cultivate students' real knowledge capability. It develops students' potential, guide and promote students to internalize ideas, characters, knowledge, ability and methods to successful quality through organizing effective teaching activities. This teaching mode is an advanced mode which is generally adopted by worldwide colleges. Such teaching mode mainly stresses students as the teaching subject, pays attention to mobilizing and guiding students' enthusiasm to gain better teaching effect.

Classroom organization with exploitation internalization teaching method is composed of the following parts: teachers assign teaching tasks; arrange students to read teaching contents and references; finish three exercises; teachers take quizzes or classroom discussions; teachers explain and answer doubts. Through daily teaching organization, students' initiative can be exerted. But, in order to enhance effects, daily evaluation system is required to provide guarantee.

Daily teaching evaluation system mainly consists of the following parts: (1) class attendance (10\%); (2) class attendance (20\%), mainly check students' understanding of teaching contents or classroom discussion; (3) tax calculation (30\%). For tax law course, tax calculation is quite significant. This part is mainly reflected in three exercises. This part mainly inspects students' analysis and calculation ability. (4) Tax category memory summary table (40\%). Each Tax category involves much knowledge. It is necessary to remember much theoretical knowledge. Effective summary and memory can gain twofold results with half efforts. This part requires students summarizing according to graphs and formulas after finishing one chapter, such as graph summary according to tax payer, tax rate, taxation basis, tax calculation, tax preference and taxation management. This trains students' comprehensive analysis thinking ability and helps them be familiar with and sort teaching contents and enhance memory effects. 
The above four parts of examination and evaluation contents are the same with those carried out by many teachers except slight differences. Generally, the four pats account for $30 \%$ of total scores. Other parts can be completed in daily teaching to enhance and improve teaching effects including the following: (1) case lecture and paper (10\%). This part is finished in groups. Tax cases serve as the reference materials. Teachers put forward questions or outlines. Then, students accomplish them in groups and make reports. This part aims to test students' presentation skill, knowledge reading and searching ability, knowledge comprehension and application ability. This can deepen students' cognition and boost their quality. But, reporting time for groups is long, so it is organized once or twice in a semester; (2) tax declaration form filling (20\%), mainly involving five tax categories: added-value tax, consumption tax, business tax, corporate income tax and individual income tax. In tax revenue work, the last tax link is tax declaration and tax payment. It is very important to cultivate the ability in this aspect. Paper tax declaration form or excel can be completed. The score of this part can be evaluated according to the completion situation; (3) team simulation of tax process (10\%). Post cognition, tax registration, taxpayer identity cognizance, invoice purchase and use, tax certification preparation, account book registration, tax declaration form filling and tax declaration process can be completed in groups through tax teaching software. The score is evaluated according to team performance and completion situation.

2. Quality-based topic in the end of the term

At the end of the term, traditional paper examination is very necessary. But the form and content of the questions can be properly adjusted. Traditional examination paper is composed of single choice, multiple choice, true or false questions and calculation. Traditional examination paper puts particular emphasis on particular emphasis on. Thus, students can easily form the habit of making effort at the last moment. The teaching effect cannot be reflected. Quality-based topic can contain theoretical examination questions in traditional paper examination and add examination of practice knowledge. Quality-based topic of tax law course can include choice question (including single choice, multiple choice and undefined term), case analysis, tax calculation and tax declaration table, accounting for $30 \%$ of total scores. The examination form can adopt semi-closure form.

Semi-closure examination means students can carry a piece of A4 paper and write their summary of the course on the paper as reference, including key points, difficult points and difficult formulas etc. Such mode can examine students' comprehensive understanding and effective mastery of knowledge points. Compared with traditional closed-book examination, students can realize the transformation from closed-book examination to comprehensive ability.

Compared with general traditional question types, quality-based topic adds undefined choice question, case analysis and tax declaration form. Undefined choice question mainly examines students' memory, comprehension, synthesis and analysis ability. It can examine the contents remembered, comprehension and knowledge application level. Single choice and multiple choices can cultivate students' comprehension of knowledge, principles as well as knowledge integrality. Case analysis mainly adopts tax cases in current events. The tax cases are mainly tax evasion cases. Students are required to find out calculation problems, declaration problems, collection and management problems. Quality-based topic can help students better understand teaching knowledge, combine practice work and cultivate students' professional quality. Tax declaration form is an important content of tax accounting practice. Completion of this content is a basic requirement of tax accounting and shows the requirement of practical ability.

3. Super-value credit evaluation

In the final examination in colleges, many students pursue "60 scores are perfect and 61scores are redundant". This is because you can gain the same credit for 60 scores and 100 scores. Thus, they will not make perfection more perfect during learning professional knowledge and mastery of professional ability. In combination of this circumstance, to make students better learn tax law course and improve course effect, it is necessary to make students make perfection more perfect through super-value credit. The effect can be for the sake of future examination, improvement of understanding tax law knowledge and mastery of tax work. Super-value credit can be set in this way: 60-80 scores gain foundation credit; 81-90 scores gain foundation credit x $(1+10 \%)$; 91-95 scores 
gain course credit $x(1+20 \%) ; 76$ scores and above gain foundation quality credit $x(1+50 \%)$. The implementation of such super-value credit mechanism can promote students to learn tax law course more carefully. Gaining more credits in one course can provide material help for them to graduate in advance or for other arrangements.

4. Other evaluation method

Apart form the above three examination and evaluation modes, there are also other modes. For instance, it is very hard for teaching materials and revenue laws to reach complete synchronization and connection. Students can be required to collect and sort the latest revenue laws and regulations so as to evaluate their collecting and sorting ability. In tax law course teaching, students are faced with direct business problems which have been handled. In practical work, they are faced with bills and contracts in economic business. Therefore, teachers can give students some original tax vouchers to examine their ability to analyze and handle original materials.

Implementation of exploitation internalization teaching method for assessment at ordinary times, quality-based topic in the end of the term and super-value credit in tax law course teaching reflect new thoughts and new explorations of current examination modes, stock to student-centered principle and the principle of mobilizing students' subjective initiative and implementing practice first, enhance cultivation of applied talents and actually improve students' employment ability.

\section{References}

[1] Zhao Zuobin, Theory and practice of successful quality-oriented education in colleges [M]. Wuhan University Press, 2009.1:224-235

[2] Xiao Lu, Study on tax law teaching in major of application-oriented undergraduate accountancy [J]. Exchange and Discussion, 2013.2 (II): 224-224

[3] Wei Suyu, On "tax law" teaching reform for tax administration major [J]. Theory and Practice of Contemporary Education, 2012.10:90-91

[4] Chen Yanyan, Tax law teaching: how to link theory with practice [J]. Vocational Education, 2013.4:215-216

[5] Ling Huixian, On tax law teaching reform based on applied talents [J]. Securities \& Futures of China, 2012.6:296-296

[6] Shen Yanyan, Study on tax law teaching reform in accounting major. Co-operative Economy \& Science [J]. 2011.10:118-119 